\title{
FEATURES OF VENTILATION DISORDERS IN PATIENTS WITH HYPERTENSION
}

\author{
Levchenko Valerii Anatoliiovych, Doctor of Medicine, professor, Ivano-Frankivsk national medical \\ university, Ivano-Frankivsk, Ukraine \\ Vakaliuk Ihor Petrovych, Doctor of Medicine, professor, Ivano-Frankivsk national medical \\ university, Ivano-Frankivsk, Ukraine \\ Ovchar Anna Ihorivna, assistant, Ivano-Frankivsk national medical university, Ivano-Frankivsk, \\ Ukraine
}

Zarivna Iryna Volodymyrivna, assistant, Ivano-Frankivsk national medical university, Ivano-Frankivsk, Ukraine

Maksymiak Mariana Viktorivna, assistant, Ivano-Frankivsk national medical university, Ivano-Frankivsk, Ukraine

DOI: https://doi.org/10.31435/rsglobal_conf/30122020/7347

Abstract. The signs of hyperventilation syndrome are detected among hypertensive patients, but are not noticed by doctors that in some way can complicate the progression of the hypertension. It was established during the research that for the hypertensive syndrome and its extent of reveal verification, besides standardized Nijmegen questionnaire spirometry or diaphragm amplitude can be used. It was established, that among group of hypertensive patients ( $n=43)$ with the signs of hyperventilation syndrome, the decrease of lung ventilation figures in accordance to proper magnitude was revealed. Specifically, such figures as vital capacity, forced expiratory volume in 1 sec, inspiratory and expiratory reserve volume, peak expiratory flow were accurately lower. The reveled changes increased after conducting of the hyperventilation probe among all patients of the main group. At the same moment only among 28,57 \% of patients from control group ( $n=14)$, without signs of hyperventilation syndrome, according to the survey, the violation of lung ventilation from slight $(21,43 \%)$ to moderate $(7,14 \%)$ was revealed under the hyperventilation probe. Besides that, among patients from the main group the limitation of diaphragm amplitude was noticed in comparison to results gained in the control group which became stronger under the forced breathing. The revealed changes among hypertensive patients require on time diagnostic and correction.

Keywords: arterial hypertension, hyperventilation syndrome, spirometry, ultrasound scanning of diaphragm.

Introduction. Arterial hypertension is the main risk factor of premature mortality, stroke, myocardial infarction and other cardio-vascular complications. Nowadays arterial hypertension is diagnosed among 30\% of Ukrainians (Sirenko, 2016). Arterial hypertension (AH) - is the result of the disorders of blood pressure (BP) regulations at any level of homeostasis. The main role at the BP regulation, except neurohumoral impact, and basal vascular tone belongs to respiratory system.

During the studies the respiratory system is partially observed as a "target-organ" under the $\mathrm{AH}$, that is associated with subclinical inflammation of its structures, dysfunction of the endothelial, lungs capacity to the ACE synthesis, destruction of the angiotensin, reveals of alveolar hyperventilation (Abrosimov, Glotov \& Zhukova, 2015; Filatova, 2006; Nazarov, 2013). Also in the last century lots of researchers indicated shortness of breath, "asthma in hypertension patients" among some number of hypertension patients under the absence of signs of the insufficiency of the left ventricular (Abrosimov, Glotov \& Zhukova, 2015; Bass, 2004).

In recent years the number of reports concerning the reveals of the hyperventilation syndrome (HVS) has increased in the sufficient number of hypertensive patients (43-75\%) (Abrosimov, Glotov \& Zhukova, 2015; Filatova, 2006). HVS leads to the increase of the BP level through the mechanisms of hypocapnia and respiratory alkalosis, the increase of intracellular $\mathrm{Ca}^{2+}$, arteriole spasm, the increase of total peripheral vascular resistance, the change in the chemoreceptor's activity. Whereas it has been indicated the violation of local autoregulation processes, angiospastic reconstruction, including cerebral channel. It has been established that decrease of $\mathrm{CO}_{2}$ tension in the arterial blood by $1 \mathrm{~mm} \mathrm{Hg}$ leads to the decrease of vessel radius by $1.4 \%$, and $\mathrm{CO}_{2}$ tension in the arterial blood to $30-32 \mathrm{~mm} \mathrm{Hg}$ leads to the decrease of vessel radius nearly by $15 \%$, that shorten the bloodstream to $56 \%$ under the 
rate and results into severe ischemia of brain cells (Agadzhanyan, Mishustin \& Levkin, 2014; Kobalava, Kotovskaya \& Mil'to, 2002).). Meanwhile the neurons of vascular center react on the ischemia by severe stimulation. As a result, the systemic arterial pressure increases up to as maximum level as can be provided by the heart pump function. Such increase of the systemic BP, on the background of hypocapnia, is aimed at the improvement of cerebral bloodstream that in such situations does not lead to full removal of ischemia in such patients (Abrosimov, Glotov \& Zhukova, 2015). Hence HVS in case of hypertension from entiopathogenenic and clinical positions means much more than rapid breathing (Urban, Shchekotov \&Varlamov, 2011).

Polymorphism of HVS clinical reveals causes problems with diagnosis, recreation and treatment, as the studies on cardiovascular systems, autonomic regulations under $\mathrm{AH}$ take the dominant place in the existing scientific literature against this background breathing disorders are in the shade without sufficient analysis and correction (Agadzhanyan, Mishustin \& Levkin, 2014; Veyn \& Moldovanu, 1988).

Therefore, the research on the state of the hypertension patients' respiratory system is highly relevant, as it allows objectifying the progression of HVS, to develop the ways of its correction, as medical hypertensive therapy does not influence on the appearance of hypocapnia and its consequences.

\section{Materials and methods of the investigation. \\ Participants and Procedure}

The main group in the given research consists of 43 patients, women $(62,79 \%)$ and men (37,21\%), at the age of 43-62 who have been on a register concerning hypertension I-II stage with verified signs of the hyperventilation syndrome. The Ukrainian Cardiologists Association's recommendations and ESC/ESH (2018) were followed for the diagnostic of AH. Standardized Nijmegen questionnaire, which has 16 points, was used for indicating of the hyperventilation syndrome and the results were evaluated in accordance to 5 points scale (0-never, 4-very often). Especially, symptoms occurred rarely - less than 1 time a month, sometimes more often than 1 time a month, often -1 time a week or even more often - 1 time a day or more. Minimum and maximum points were " 0 " and " 64 ". The test results' assessment - if the total of points $<22$, test was considered as slightly possible, at the total $\geq 23$ the possibility of HVS was high, the last group as included into the further research.

The control group consisted of 14 hypertensive patients with the 1-2 stage without symptoms of HVS at the age of 40-56 years. Patients had not taken the hypotensive treatment 6-7 days before the research.

Patients with the III stage of hypertension, drug resistant form of hypertension associated clinical states the secondary $\mathrm{AH}$, bronchopulmonary disease, obesity, patients with diabetes were not included in the research. 8 patients ( 5 women and 3 men) from the main group and 3 patients from the control group were smokers.

The research was conducted with the respect for main bioethical statements of Council of Europe Convention (1994).

\section{Instruments}

The volume and speed values of outer breathing were measured by digital spirometer (Spirocom medic chai, the UK) in accordance to standard method with the analysis of spirography values and the "stream-volume" curve (Baranov, Kurenkova \& Kazantsev, 2002). Whilst the performing of the spirometry it was studied the volume speed of air stream, the volume indicators of the respiratory system. In particular, it was indicated vital capacity (VC), inspiratory vital capacity (IVC), expiratory vital capacity (EVC), forced lung capacity (FVC), the volume of forced exhale for $1 \mathrm{sec}$ (FEV1), reserve volume of inhale and exhale (IRV, ERV), the peak expiratory flow (PEF), inspiratory time (I_TIME) and expiratory time (E_TIME). Spirometry was performed at the state of calm and after hyperventilation probe.

Hyperventilation probe (HVPr) was performed in the morning in the lying position and on an empty stomach to provoke the hypocapnia. Heart rate (HR) and BP were registered and spirometry has been performed before the research. HVPr consisted in performing rapid forced inhales and exhales during the 30-45 sec in case if it was not enough to the occurring of the dizziness (Balef, 2007). Immediately after it the BP and HR were measured, the spirometry was conducted in both control and main groups. Hyperventilation probe was considered positive, in case when HR changes were 
revealed, BP did not turn back to initial numbers in three minutes after the probe had finished. In the case of hidden hyperventilation syndrome, the signs of hypocapnia were observed during $\geq 20 \mathrm{~min}$. In this investigation hyperventilation probe was treated as the factor of stress tension.

The functional state of the main inspiratory muscle and diaphragm was evaluated by the indicating of the amplitude its right edge with the help of ultrasound scanner "Alpinion dimonds 9" (South Korea). Ultrasound investigation of the diaphragm's right edge was performed in the state of calm and forced breathing. Amplitude of the diaphragm was measured among hypertensive patients (main and control groups) and among mainly healthy people $(\mathrm{n}=12)$ at the age 37-54. The body mass index (BMI) was measured in accordance to standard methods BMI $\left(\mathrm{kg} / \mathrm{m}^{2}\right)=$ Weight $(\mathrm{kg}) / \mathrm{Height}^{2}\left(\mathrm{~m}^{2}\right)$.

Statistical analysis

For the assessment of the degree of credibility research results' it was applied the variantstatistic method for getting the results with the usage of packet Statistica v. 6.1 (USA). The method of approximation was also used in order to predict and assess the results in Excel. It was used the polynomial type of approximation which is the most successful in situation when data is always changeable state.

\section{The results of the study and their discussion}

All patients in the main group had sustained increase of BP which did not decrease autonomously. Arterial hypertension of the I stage was diagnosed in 28 patients - systolic blood pressure (SBP) $(149,89 \pm 1,03) \mathrm{mm} \mathrm{Hg}$, diastolic blood pressure (DBP) $(86,04 \pm 1,39) \mathrm{mm} \mathrm{Hg}$. The II stage of AH was revealed in 15 patients - SBP $(164,2 \pm 1,13) \mathrm{mm} \mathrm{Hg}$, DBP - $(92,20 \pm 1,11) \mathrm{mm} \mathrm{Hg}$. The BP in the control group was the next - systolic $(150,71 \pm 2,11) \mathrm{mm} \mathrm{Hg}$, diastolic $-(67,42 \pm 1,51) \mathrm{mm} \mathrm{Hg}$. The duration of hypertension was $(5,71 \pm 0,30)$ years in the main group and $(6,14 \pm 0,36)$ years in the control group.

BMI among examined patients of the main group was under I stage of AH 27,66 $\pm 0,34$ points, under the II stage $-28,19 \pm 0,43$ points. In the control group of hypertensive patients BMI was $28,60 \pm 0,37$ points, in the group of mainly healthy people $-27,70 \pm 0,40$.

The analysis of Nijmegen questionnaire showed that in the group of patients with the I stage of $\mathrm{AH}$ at the background of HVS the average point was $(30,61 \pm 0,87)$, under the II stage of hypertension the average point was higher than $(35,20 \pm 1,43)(\mathrm{p}<0,05)$. The result of questionnaire in the control group of patients was $(18,42 \pm 1,12)$ points.

Among the complaints in the patients of this group with the I stage of AH were often observed dizziness $(53,57 \%)$, short breath $(46,43 \%)$, rapid and deep breath $(32,14 \%)$, darkened vision $(35,71 \%)$. Under the II stage of AH dizziness was observed in $60 \%$ patients, and among 46,67\% - were observed inability to breathe deeply and also darkened vision, tremor of fingers and face numbing - in 33,33\% of patients, rapid and deep breathing, sense of fear were revealed in $26,67 \%$ cases etc.

Furthermore, among some patients of the main group were revealed hyperventilation equivalents presented by periodical cough $(23,26 \%)$ and yawning $(27,92 \%)$, episodic involuntary sighs at the state of calm and sniffling $(11,63 \%)$. Also there were observed prompt fatigability, general weakness among the patients during the day.

Researchers of outer breathing function conducted at the state of calm among patients with I and II stage of AH revealed the next changes: according to the spirometry values figures of IVC in case I and II stage of AH were $(72,09 \pm 1,93) \%$ and $(65,51 \pm 2,29) \%(p<0,05)$, accordingly, were lower than the norms $(84,62 \pm 2,78) \%$. Also accurately lower from the relevant were values of EVC among patients with I and II stage of hypertension, correspondingly $(78,27 \pm 1,77) \%$ and $(73,87 \pm 1,8) \%$. The values of FVC among such patients were $(77,23 \pm 1,59) \%$ and $(72,91 \pm 1,88) \%$ which were lower than the norms $(82,18 \pm 1,93) \%$. A similar pattern was pointed out in FEV1 values, in patients with the I stage of $\mathrm{AH}-(76,11 \pm 2,0) \%$; in patients with the II stage of $\mathrm{AH}-(68,72 \pm 2,93) \%$, the last ones were accurately lower than the norms. Also accurately lower were values of ERV under I and II stage of hypertension, correspondingly $(50,08 \pm 3,32) \%$ and $(48,28 \pm 4,38) \%$ in comparison to appropriate figures $(58,12 \pm 3,41) \%$. Identical changes were revealed at the IRV. Slightly decreased in comparison to appropriate figures were ones of PEF among hypertensive patients with the I stage of AH $(73,84 \pm 3,14)$ $\%(\mathrm{p}>0,1)$ and among patients with the II stage of AH $(65,08 \pm 1,38) \%(\mathrm{p}<0,05)$. Also among patients with I and II stage of AH was measured the decrease of inhale time $(p<0,05)$, mean while E_TIME in both groups at the state of calm, did not go under any changes (Table 1). 
The analysis of spirometry results at the state of calm, with taking into consideration Klements recommendations (1994), revealed among 25 patients with I and II stage of AH $(58,14 \%)$ disorders of lungs ventilations around slight changes. In $27,91 \%$ patients were revealed moderate and drastic changes, and adequate and conventionally adequate were registered in $13,95 \%$ patients.

Table 1. Spirometry values in hypertensive patients with the I and II stage of AH in accordance to adequate values

\begin{tabular}{|c|c|c|c|c|c|}
\hline \multirow{2}{*}{ Values } & \multicolumn{2}{|c|}{ I stage AH $(\mathbf{n = 2 8})$} & \multicolumn{2}{c|}{ II stage AH (n=15) } & \multirow{2}{*}{$\begin{array}{c}\text { Appropriate } \\
\text { indicators }\end{array}$} \\
\cline { 2 - 5 } & A & B & A & B & $84,62 \pm 2,78$ \\
\hline IVC, \% & $72,09 \pm 1,93^{*}$ & $66,47 \pm 1,80^{*}$ & $65,51 \pm 2,29^{*}$ & $56,13 \pm 1,24^{*}$ & $86,45 \pm 2,67$ \\
\hline EVC, \% & $78,27 \pm 1,77$ & $72,77 \pm 1,49$ & $73,87 \pm 1,80^{*}$ & $64,47 \pm 1,32$ & 86,45 \\
\hline IRV, \% & $50,08 \pm 3,32^{*}$ & $46,70 \pm 2,57$ & $48,28 \pm 4,38^{*}$ & $38,96 \pm 2,44$ & $58,12 \pm 3,41$ \\
\hline ERV, \% & $28,44 \pm 5,27^{*}$ & $27,16 \pm 3,09$ & $23,07 \pm 3,81^{*}$ & $18,39 \pm 2,33$ & $36,53 \pm 2,94$ \\
\hline FVC, \% & $77,23 \pm 1,59$ & $70,10 \pm 1,51$ & $72,91 \pm 1,88^{*}$ & $61,06 \pm 1,57$ & $82,18 \pm 1,93$ \\
\hline FEV1, \% & $76,11 \pm 2,00^{*}$ & $70,14 \pm 1,42$ & $68,72 \pm 2,93$ & $59,88 \pm 1,70$ & $82,58 \pm 2,10$ \\
\hline PEF, \% & $73,84 \pm 3,14$ & $70,51 \pm 2,36$ & $65,08 \pm 1,38^{*}$ & $63,21 \pm 1,74$ & $78,85 \pm 1,92$ \\
\hline I_TIME, sec & $1,37 \pm 0,04^{*}$ & $1,31 \pm 0,04$ & $1,46 \pm 0,08^{*}$ & $1,29 \pm 0,05$ & $1,74 \pm 0,12$ \\
\hline E_TIME, sec & $1,76 \pm 0,04$ & $1,65 \pm 0,02$ & $1,73 \pm 0,09$ & $1,59 \pm 0,05$ & $1,83 \pm 0,12$ \\
\hline
\end{tabular}

Note: $*^{*}-\mathrm{p}<0,05$ in comparison to adequate; $\mathrm{A}$ - values received at the state of calm; B values received after hyperventilation.

After hyperventilation probe, the number of patients with I-II stage of AH with slight disorders of lung ventilation decreased to $39,53 \%$, and with adequate and conventionally adequate values - to $6,98 \%$. Furthermore, the number of patients with moderate and sharp changes accurately increased to $53,49 \%$.

After completing of HV probe in some patients of main group $(34,88 \%)$ were revealed dizziness (vertigo), tinnitus, lack of fresh air, yawning at duration from 5 to 10 minutes.

Apart from that, after 3,45 $\pm 0,06$ minutes after hyperventilation probe in patients with I stage AH systolic blood pressure turned out to be increased on $5,72 \%-(158,46 \pm 0,99) \mathrm{mm} \mathrm{Hg}(\mathrm{p}<0,05)$, diastolic - showed only tendency to increase $(\mathrm{p}>0,05)$. In the group of patients with II stage of AH systolic blood pressure after 3,49 $\pm 0,09$ minutes of completing of hyperventilation probe increased from $(162,20 \pm 1,13) \mathrm{mm} \mathrm{Hg}$ to $(167,93 \pm 1,28) \mathrm{mm} \mathrm{Hg}(\mathrm{p}<0,05)$, meanwhile the diastolic blood pressure did not go under changes.

In control group of patients, after $(3,18 \pm 0,02)$ minutes of hyperventilation probe was finished, SBP $(150,71 \pm 2,70) \mathrm{mm} \mathrm{Hg}$ accurately was not different in comparison to input data $(145,07 \pm 2,17) \mathrm{mm} \mathrm{Hg}$ ( $>00,1)$; however, it was revealed the moderate decrease of DBP - from $(80,3 \pm 1,73 \mathrm{~mm} \mathrm{Hg}$ to $(75,64 \pm 1,12) \mathrm{mm} \mathrm{Hg}(\mathrm{p}<0,05)$.

That is why the reliable increase of $\mathrm{BP}$ among patients of the main group after hyperventilation probe may indicate the increase of sympathetic activity and presence of hypocapnia. At the same time hyperventilation among healthy people may lead to decrease of arterial pressure and even syncope in accordance to the literature (Bass, 2004).

Also after hyperventilation probe were revealed changes of the spirometry values which reflected the worsening of voluminous and velocity values of the lung ventilation among patients of the main group. Specifically, for I and II stage of the AH the IVC values decreased on 7,8\% and $14,32 \%$ correspondingly; EVC - on 7,03\% and 12,8\%, IRV - on 6,75\% and 19,5\%. Under this level of validity according to the method of approximation among patients with I stage of AH values were $\mathrm{R}^{2}=0,8001$ and $\mathrm{R}^{2}=0,9984$ - under 2 type of $\mathrm{AH}$ (Figure 1).

In the control group of patients according to spirometry after hyperventilation probe were revealed adequate and conventionally adequate values in $71,43 \%$ of patients, slight changes - in $21,43 \%$ of patients, moderate - in one person $-7,14 \%$. So, among patients of this group within $(3,18 \pm 0,02)$ sec after compliting of hyperventilation probe in the major part of the patients received results were not reliably different from the initial values. But in $28,57 \%$ of patients the values of lung ventilation had worsened that could be a sign of hidden respiratory disfunction. 


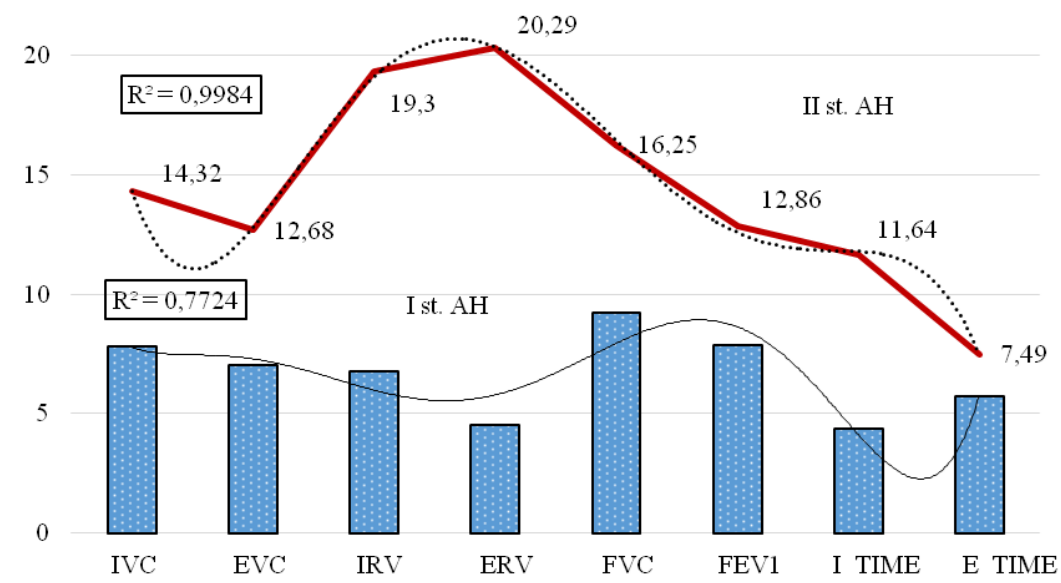

Fig.1. Level of decrease in spirometry values among patients with AH after hyperventilation probe (\%)

Discussion. The obtained results, during the research in the main group of patients with $\mathrm{AH}$, have allowed us to say that besides complaints, the reveals of hyperventilation syndrome go with the changes of spirometry values, which are highly observed among patients with the II stage of AH. Meanwhile the changes of investigated values have reliably worsened after performed hyperventilation probe, that according to the spirometry data have been accompanied by increasing of the number of patients with moderate and abrupt changes. The obtained results of spirometry changes under I and II stage of $\mathrm{AH}$, in case of the absence of bronchopulmonary disorders, can occur as a result of breathing neural regulations disorders under $\mathrm{AH}$ - disintegration of upper segmental and segmental units of vegetative nervous system, sustained initiation of the pressing centers, violation of the pattern breathing hyperventilation.

According to the literature (Zureik, 2001), the analysis of FEV1 values and the speed of pulsed wave among almost healthy men of the average age without ischemic heart disease and $\mathrm{AH}$ has revealed that independently from all indicated risk factors of atherosclerosis, decrease of FEV1 has been connected with the increase of the speed of pulsed wave. That is why the increase of the speed of pulsed wave, which occurs under the hypertension, can lead to decrease of the speed values of the lung ventilation in such category of patients.

The major role in the formation of the normal breath pattern plays the diaphragm's amplitude that is why the research of its state at the background of hyperventilation syndrome among hypertensive patients is of interest. The performed ultrasound investigation of the functional state of the main diaphragm inspiratory muscle, revealed that in patients with the I stage of $\mathrm{AH}(\mathrm{n}=16)$, and in patients with the II stage of $\mathrm{AH}(\mathrm{n}=12)$ was revealed the decrease of the amplitude. It was established that in the state of calm breathing in these patients, the values were correspondingly $(19,31 \pm 0,62) \mathrm{mm}$ $(\mathrm{p}<0,05)$ and $(16,75 \pm 0,45) \mathrm{mm}(\mathrm{p}<0,05)$, against the result $(23,25 \pm 1,12) \mathrm{mm}$, received in the control group of patients $(n=12)$. In the group of almost healthy people $(n=12)$ the value were $(26,08 \pm 0,87) \mathrm{mm}$.

Besides that, in 4 patients with the II stage of $\mathrm{AH}$ and in 2 patients with the I stage of $\mathrm{AH}$, - was indicated the reliably thickening of the outer parts (muscle part) of the diaphragm, that in average was $(12,40 \pm 1,50) \mathrm{mm}$ against average values $(7,20 \pm 1,25) \mathrm{mm}$ received in the group of almost healthy people. It could signal about a hypertrophy of the diaphragm in these patients as a result of constant strain.

The studies of the diaphragm amplitude under the forced breathing in patients with I and II stage of AH revealed reliably restriction of its movement, correspondingly $(62,13 \pm 1,89) \mathrm{mm}$ and $(54,55 \pm 1,25) \mathrm{mm}$, in accordance to the results received in the control group of patients $(66,25 \pm 1,37) \mathrm{mm}$ and almost healthy people $-(74,17 \pm 1,77) \mathrm{mm}$.

The similar decrease of the diaphragm amplitude causes the formation of the shallow and rapid respiration worsening of the lung ventilation values hypocapnia and as a result hypoxia that is indicated in the state of stressful tension.

The decrease of diaphragm's amplitude under AH can be the sign of breathing neurological regulation dysfunction that is connected with the worsening of functional activity of the motor neurons of the spinal cord at the level C3-5, neurons of breathing center hypothalamic structures. 
That is why changes of the functions of outer breathing values can be registered among the patients with $\mathrm{AH}$ even under the absence of comorbid function from the respiratory system, deficiency of blood circulation. Untimely diagnostic and correction of hypocapnia reveals in hypertensive patients can lead to the destabilization of illness, decrease of prescribed medical treatment efficiency, and development of refraction under the treatment of AH (Filatova, 2006).

In this case as the additional diagnostic method for revealing or confirmation of respiratory dysfunction in such type of patients can be spirometry and evaluation of diaphragm's amplitude in the state of calm and under the hyperventilation probe (Kobalava, Kotovskaya \& Mil'to, 2002).

The emphasis on the medical therapy only sometimes precludes conducting the correction of the modified risk factors and to removing signs of hypocapnia and its consequences.

\section{Conclusions.}

1. In major part of patients the combination of arterial hypertension with the hyperventilation syndrome is characterized as reliable decrease of lung ventilation values, diaphragm's amplitude values as in the state of calm as under the hyperventilation probe.

2. It is necessary to conduct spirometry, detecting of diaphragm's amplitude values as in the state of calm as under the hyperventilation probe for objectivity of the hyperventilation syndrome under $\mathrm{AH}$ except the questionnaire.

3. Timely diagnostic of hyperventilation syndrome will allow increasing the efficiency of the hypertension medical treatment by the additional usage of special breathing gymnastic for removing signs of hypocapnia.

Conflicts of interest. There is no conflict of interest in conducted by author's research.

\section{REFERENCES}

1. Abrosimov, V. N., Glotov, S. I., Zhukova, L. A. (2015). Mnogoobraziye sindroma odyshki pri gipertonicheskoy bolezni. Vestnik sovremennoy klinicheskoy meditsiny, 8(5), 13-18.

2. Agadzhanyan, N. A., Mishustin, YU. N., Levkin S. F. (2014). Khronicheskaya gipokapniya sistemnyy patogennyy faktor. Samara.

3. Balef, E. L. (2007). Proba s giperventilyatsiyey u bol'nykh arterial'noy gipertenziyey. Zdravookhraneniye Kazakhstana, 86(4), 29-35.

4. Baranov, V. L., Kurenkova, I. G., Kazantsev, V. A. (2002). Issledovaniye funktsii vneshnego dykhaniya. Sankt-Peterburg: Elbi-SPb.

5. Bass, C. (2004). Hyperventilation syndrome: a chimera? Journal of Psychosomatic Research, 42(5), 421-426.

6. Filatova, Y. G. (2006). Giperventilyatsionnyy sindrom: etiopatogenez, diagnostika i lecheniye. Farmateka, 7, 1-4.

7. Gardner, W., Bass, C. (2004). Hyperventilation in clinical practice. British Journal of Hospital Medicine, 41(1), 73-81.

8. Kobalava, ZH. D., Kotovskaya, YU. V., Mil'to, A. S. (2002). Refrakternaya arterial'naya gipertoniya i ozhireniye. Rossiyskiy kardiologicheskiy zhurnal, 4, 53-57.

9. Mit'kov, V. V., Nazarov, B. M., Zykov, K. A., Ratova, L. G. (2011). Prakticheskoye rukovodstvo po ul'trazvukovoy diagnostike. Obshchaya ul'trazvukovaya díagnostika. Moskva: Vidar-M.

10. Nazarov, B. M. (2013). Nuzhna li spirometriya pri serdechno-sosudistykh zabolevaniyakh?. Sistemnyye gipertenzii, 2, 69-74.

11. Sirenko, YU. N. (2016). Dinamika sostoyaniya uprugo-elastichnykh svoystv arteriy bol'nykh s arterial'noy gipertenziyey sindromom obstruktivnogo apnoe sna. Arterial'naya gipertenziya. 1 (45).

12. Urban, P. I., Shchekotov, V. V., Varlamov, P. N. (2011). Gipertonicheskaya bolezn's giperventilyatsionnym sindromom i markery povrezhdeniya endoteliya. Materialy S"yezda terapevtov Privolzhskogo federal'nogo okruga Rossii. Perm'.

13. Veyn, A. M., Moldovanu, I. V. (1988). Neyrogennaya giperventilyatsiya. Kishinev: Shtiintsa.

14. Zureik, M., Benetos, A., Neukirch, C. (2001). Reduced pulmonary function is associated with central arterial stiffness in men. American Journal of Respiratory and Critical Care Medicine, 164, 2181-2185.

15. Retrieved from http://meduniver.com/Medical/Physiology/613.html 